\title{
New insights into the reconstructed temperature in Portugal over the last 400 years
}

\author{
J. A. Santos ${ }^{1}$, M. F. Carneiro' ${ }^{1}$, A. Correia ${ }^{2}$, M. J. Alcoforado ${ }^{3}$, E. Zorita ${ }^{4}$, and J. J. Gómez-Navarro ${ }^{5}$ \\ ${ }^{1}$ Centre for the Research and Technology of Agro-Environmental and Biological Sciences, CITAB, Universidade de \\ Trás-os-Montes e Alto Douro, UTAD, 5000-801 Vila Real, Portugal \\ ${ }^{2}$ Department of Physics and Geophysical Centre of Évora, University of Évora, Évora, Portugal \\ ${ }^{3}$ Centro de Estudos Geográficos, IGOT, Universidade de Lisboa, Ed. Faculdade de Letras, 1600-214 Lisboa, Portugal \\ ${ }^{4}$ Institute for Coastal Research, Helmholtz-Zentrum Geesthacht, Geesthacht, Germany \\ ${ }^{5}$ Climate and Environmental Physics, Physics Institute and Oeschger Centre for Climate Change Research, University of \\ Bern, 3012 Bern, Switzerland
}

Correspondence to: J. A. Santos (jsantos@utad.pt)

Received: 28 November 2014 - Published in Clim. Past Discuss.: 6 January 2015

Revised: 30 April 2015 - Accepted: 15 May 2015 - Published: 5 June 2015

\begin{abstract}
The consistency of an existing reconstructed annual (December-November) temperature series for the Lisbon region (Portugal) from 1600 onwards, based on a European-wide reconstruction, with (1) five local borehole temperature-depth profiles; (2) synthetic temperaturedepth profiles, generated from both reconstructed temperatures and two regional paleoclimate simulations in Portugal; (3) instrumental data sources over the twentieth century; and (4) temperature indices from documentary sources during the late Maunder Minimum (1675-1715) is assessed. The low-frequency variability in the reconstructed temperature in Portugal is not entirely consistent with local borehole temperature-depth profiles and with the simulated response of temperature in two regional paleoclimate simulations driven by reconstructions of various climate forcings. Therefore, the existing reconstructed series is calibrated by adjusting its low-frequency variability to the simulations (first-stage adjustment). The annual reconstructed series is then calibrated in its location and scale parameters, using the instrumental series and a linear regression between them (second-stage adjustment). This calibrated series shows clear footprints of the Maunder and Dalton minima, commonly related to changes in solar activity and explosive volcanic eruptions, and a strong recent-past warming, commonly related to human-driven forcing. Lastly, it is also in overall agreement with annual temperature indices over the late Maunder Minimum in Portugal. The series resulting from this
\end{abstract}

post-reconstruction adjustment can be of foremost relevance to improve the current understanding of the driving mechanisms of climate variability in Portugal.

\section{Introduction}

Climate reconstructions allow further insight into the climatic variability beyond the relatively short instrumental period, being commonly based on early instrumental records, documentary evidence (namely, memoirs, diaries, chronicles, weather logs, ship logbooks) and natural proxies, such as boreholes, tree rings, corals, ice cores, speleothem records and pollen profiles (Brázdil et al., 2005, 2010; Camuffo et al., 2010; Li et al., 2010; Luterbacher et al., 2006; Pollack and Huang, 2000). Historical climatology is critical for understanding the driving processes of climate variability not only in the past, but also in the future. This is particularly important when developing climate change projections for the future under emission scenarios (IPCC, 2013).

Climate variability in Europe over the last millennium was reconstructed based on both documentary evidence and natural proxies (e.g. Alcoforado et al., 2000; Brázdil et al., 2005, 2010; Camuffo et al., 2013; González-Rouco et al., 2009; Luterbacher et al., 2006). European-wide temperature reconstructions since 1500 have already been developed (Luterbacher et al., 2004; Xoplaki et al., 2005), as have continental- 
wide reconstructions for the last two millennia by Ahmed et al. (2013). Temperature reconstructions in some European sites, based on both documentary data and instrumental records since the 16th century, were carried out by Camuffo et al. (2010). A temperature reconstruction for southern Portugal during the late Maunder Minimum (LMM; 1675-1715) was presented by Alcoforado et al. (2000). However, in Portugal, most of the pre-instrumental records show numerous temporal gaps and there is a substantial lack of natural proxies with clear climatic signals (Alcoforado et al., 2012; Camuffo et al., 2010; Luterbacher et al., 2006).

Borehole temperature-depth profiles can be used as paleoclimate proxies for climate reconstruction (e.g. Bodri and Čermák, 1997; González-Rouco et al., 2009; Majorowicz et al., 1999; Šafanda et al., 2007), as they provide independent information on long-term temperature variability (Jones et al., 2009). Borehole measurements are a complementary temperature record to high-frequency air temperature series recorded at weather stations and, through profile inversion methods, may also enable validating low-frequency variability in these series (e.g. Beltrami and Bourlon, 2004; Beltrami and Mareschal, 1995; Beltrami et al., 2011; Chouinard and Mareschal, 2007; González-Rouco et al., 2006; Gouirand et al., 2007; Harris and Chapman, 1998; Harris and Gosnold, 1999; Nielsen and Beck, 1989; Pollack et al., 2006). Some studies have been carried out using borehole temperature logs measured in southern Portugal (e.g. Correia and Šafanda, 1999, 2001; Šafanda et al., 2007). Borehole reconstructions can also be compared to paleoclimate simulations generated by Earth system models for validation purposes (Beltrami et al., 2006; González-Rouco et al., 2009; Stevens et al., 2008).

The present study aims at analysing the consistency between the Luterbacher et al. (2004) and Xoplaki et al. (2005) temperature reconstructions for the Lisbon region (Portugal) over the period of 1600-1999 using (1) five local borehole temperature-depth profiles; (2) synthetic temperature-depth profiles, generated from gridded near-surface temperatures produced by regional paleoclimate reconstructions and simulations; (3) instrumental data recorded in Lisbon over the twentieth century; and (4) temperature indices from early instrumental and documentary sources during the LMM (1675-1715). This analysis allows a validation of the annual mean reconstructed temperature in Portugal over the last 400 years. The identification of possible inconsistencies in the above-mentioned data sources enables a post-reconstruction adjustment of this time series. In effect, this calibrated time series may help our understanding of past climate variability in Portugal and its main driving mechanisms, namely the role of external vs. internal forcing mechanisms in temperature variability. This attribution analysis provides critical information for model validation and for assessing the reliability of regional climate change projections. The data sets and methods are presented in Sect. 2, the results are discussed in Sect. 3 and the main conclusions are summarized in Sect. 4.

\section{Data and methods}

\subsection{Reconstructed temperatures}

The reconstructed seasonal mean temperature in the grid box $38.5-39.0^{\circ} \mathrm{N}, 8.0-8.5^{\circ} \mathrm{W}$, which is located in the area of Lisbon (Portugal), for the period of 1600-1999 was extracted from the Luterbacher et al. (2004) and Xoplaki et al. (2005) European-wide reconstructions (Lut2004 henceforth). Data is originally defined on a $0.5^{\circ}$ latitude $\times 0.5^{\circ}$ longitude grid. From 1901 onwards this data set is based on instrumental data from New et al. (2000). For the selected grid box, it is largely based on temperature records from Lisbon. Since the present study focuses on annual series, annual mean temperatures were obtained by averaging the four values corresponding to winter (DJF), spring (MAM), summer (JJA) and autumn (SON) mean temperatures (no monthly data are available). Hence, annual means refer to the period from December of the previous year to November of that year (e.g. annual mean of 1710 corresponds to the average taken from December 1709 to November 1710).

\subsection{Borehole data}

The consistency of the Lut2004 reconstruction with borehole measurements, retrieved from the only geothermalpaleoclimatological observatory in Portugal $\left(38.34^{\circ} \mathrm{N}\right.$; $7.58^{\circ} \mathrm{W}$ ), is assessed. This observatory is located about $5 \mathrm{~km}$ northwest of Évora (southern Portugal) and about $100 \mathrm{~km}$ east of Lisbon. More detailed information can be found in Correia and Šafanda (2001) and Šafanda et al. (2007). Although the borehole measurements were not taken in Lisbon, the variability in the 11-year moving averages of annual mean temperatures in Évora and Lisbon is quite similar (not shown). In fact, the correlation coefficient is about 0.98 in their common instrumental period (1941-1999). The means for Lisbon and Évora are 16.8 and $15.8^{\circ} \mathrm{C}$, respectively, while both standard deviations are ca. $0.3^{\circ} \mathrm{C}$. Hence, these borehole measurements are assumed to be representative of the measurements made in Lisbon, as they mostly capture long-term variability.

Five measurements (temperature logs) in the same borehole, TGQC1, are considered herein; they were carried out on 24 March 1997 (M1), 27 March 2000 (M2), 14 November 2002 (M3), 26 November 2003 (M4) and 28 October 2004 (M5). These five temperature logs were obtained by measuring the equilibrium temperature with a thermistor every $5.0(\mathrm{M} 1), 1.0(\mathrm{M} 2), 2.5(\mathrm{M} 3$ and M4) and $2.0 \mathrm{~m}$ (M5) down to a depth of $\sim 190 \mathrm{~m}$ in the borehole. The borehole is located in a region where the typical vegetation is old cork trees. This vegetation type has not changed in the last 100 years, and the topography is subdued, with small elevation variations of tens of metres in the nearest few kilometres. The rock type in the area is Hercynian age granite. Its thermophysical properties were measured in four samples, 
collected in a quarry located in the same granitic body and $1.5 \mathrm{~km}$ eastwards of the borehole. Thermal conductivity values of $2.8 \pm 0.2 \mathrm{~W} \mathrm{mK}^{-1}$ and thermal diffusivity values of $1.3 \pm 0.1 \mathrm{~m}^{2} \mathrm{~s}^{-1}$ were measured on polished surfaces of rock samples. Heat production was calculated as $2 \pm 1 \mathrm{~W} \mathrm{~m}^{-3}$ (Correia and Šafanda, 2001). The estimated heat flux density for the borehole is $60 \mathrm{~mW} \mathrm{~m}^{-2}$, which was confirmed as an a posteriori value of $58 \pm 13 \mathrm{~mW} \mathrm{~m}^{-2}$ using the functional space inversion method of Shen and Beck (1992).

The borehole temperature-depth profiles are herein compared to synthetic temperature profiles (forward model), generated from both Lut2004 and annual mean near-surface temperatures from two paleoclimate simulations, rather than applying the conventional procedure of inverting temperature $\operatorname{logs}$ to reconstruct ground surface temperatures (e.g. Correia and Šafanda, 2001). However, the uncertainties inherent in these inversion models (Hartmann and Rath, 2005), mostly due to errors in the estimation of subsurface parameters, are also present in these forward models. The profiles were generated following the methodology described by Beltrami et al. (2011), as explained below.

The temperature anomaly at depth $z$ and time $t$, due to a step change in surface temperature $T_{0}$, is given by the solution of the one-dimensional heat diffusion equation (Carslaw and Jaeger, 1959):

$T(z, t)=T_{0} \operatorname{erfc}\left(\frac{z}{2 \sqrt{k t}}\right)$,

where erfc is the complementary error function and $k$ is the subsurface thermal diffusivity (Cermak and Rybach, 1982). It has a value of $1.3 \times 10^{-6} \mathrm{~m}^{2} \mathrm{~s}^{-1}$, according to measurements on cut and polished surfaces of local rock samples (Correia and Šafanda, 2001). Generalizing this solution for a series of $K$ step changes at the surface, the induced temperature anomalies at depth $z$ are given by Mareschal and Beltrami (1992):

$$
\begin{aligned}
& T_{t}(z)=T_{i}(z)+\sum_{j=1}^{K} T_{j}\left[\operatorname{erfc}\left(\frac{z}{2 \sqrt{k t_{j}}}\right)\right. \\
& \left.-\operatorname{erfc}\left(\frac{z}{2 \sqrt{k t_{j-1}}}\right)\right],
\end{aligned}
$$

where $T_{i}(z)$ is the initial temperature profile.

\subsection{Paleoclimate simulations}

The two paleoclimate simulations were carried out with the global circulation model (GCM) ECHO-G and then dynamically downscaled with the regional climate model (RCM) MM5. ECHO-G combines the HOPE-G ocean model (Legutke and Voss, 1999) with the ECHAM4 atmospheric model (Roeckner et al., 1996). The regional model employs a limited area domain that spans the Iberian Peninsula completely with a spatial resolution of $30 \mathrm{~km}$. Three reconstructed external forcings were used to consistently drive both models: solar variability, atmospheric greenhouse gas concentrations and radiative effects of stratospheric volcanic aerosols. The skill of the MM5-ECHO-G setup to reproduce the climate in the Iberian Peninsula has been previously evaluated by Gómez-Navarro et al. (2011), particularly with respect to the ability of the regional model to reduce the warm bias and to correct the winter variability over western Iberia in the GCM run. Two paleoclimate simulations (Sim1 and Sim2), only differing in their initial conditions, were used as a broad estimation of the effect of internal variability (cf. Gómez-Navarro et al., 2012; González-Rouco et al., 2003; Zorita et al., 2005, 2007). Near-surface ( $2 \mathrm{~m})$ temperatures for the period of 1600-1989 are extracted from these simulations. Their daily mean fields were bilinearly interpolated from the original MM5 grid to the reconstructed temperature grid $\left(0.5^{\circ}\right.$ latitude $\times 0.5^{\circ}$ longitude $)$ and extracted for the above-defined Lisbon grid box $\left(38.5-39.0^{\circ} \mathrm{N}, 8.0-8.5^{\circ} \mathrm{W}\right)$. Annual (December-November) means were then computed from the raw 6-hourly data.

In order to identify low-frequency variability and trends in the paleoclimate simulations, a data-adaptive filtering, based on a singular spectral analysis (SSA), is applied (Ghil and Vautard, 1991). SSA is based on the well-known principal component analysis, in which multiple dimensionality is achieved by including time-lagged replicas of the original time series. The resulting principal components are thus linear combinations of different lags of this series, which is equivalent to a time filtering with filter coefficients that are related to the eigenvectors of the lagged-covariance matrix. More formally, SSA corresponds to an eigenvalue decomposition of a lagged-covariance matrix, with a Toeplitz structure, obtained from the original time series of the paleoclimatic simulations. The rank, $M$, of this matrix is the average of $N / 4-N / 3$, where $N$ is the time series length (Plaut and Vautard, 1994). For the paleoclimatic simulations $M=113$ $(N=390)$. In this methodology, the original time series can also be decomposed into a sum of $M$ additive components and can be partially rebuilt using only the leading "signal modes", thus filtering out background noise components (Elsner and Tsonis, 1996; Vautard et al., 1992). In $n$-order SSA filtering, the leading $n$ modes are used to rebuild the original time series. The lower the number of retained modes, the stronger the time series smoothing. If all $M$ modes are used, the original time series is fully recovered.

Under the assumption that the aforementioned external forcings used in the paleoclimate simulations are mainly manifested by long-term temperature trends in western Iberia, as suggested by Gómez-Navarro et al. (2012), similar trends of reconstructed and simulated temperatures should be expected. As SSA enables isolating data-adaptive nonlinear trends in the time series (Ghil and Vautard, 1991), it can be used to correct discrepancies between long-term trends of reconstructed and simulated temperature series. In the present study, this approach was used to adjust the lowfrequency variability in the reconstructed series to the paleo- 
climate external forcings obtained from the simulations (adjustment of the Lut2004 reconstruction). Therefore, instead of developing a new reconstruction, an adjustment of the already existing reconstruction was carried out herein (postreconstruction adjustment).

\subsection{Instrumental data and indexed temperatures}

The consistency of the Lut2004 reconstruction with the corresponding instrumental series (InstT) for the available period of 1901-1999, recorded at the Lisboa-Geofísico meteorological station and supplied by the European Climate Assessment and Dataset project (Klein Tank et al., 2002), was also assessed. It should be stressed that Lut2004 is heavily dependent on InstT, as previously stated, and a high temporal correspondence between these two time series is thereby expected. A transfer function between InstT and Lut2004 was determined by using a linear regression analysis. The resulting first-order regression polynomial was applied so as to calibrate the Lut2004 reconstruction in the extended period from 1600 onwards, thus correcting its location and scale parameters. Lastly, annual indexed temperatures for southern Portugal over the pre-instrumental period of 1675-1715 (LMM), developed by Alcoforado et al. (2000), were also analysed for consistency assessment.

\section{Results}

\subsection{Consistency with borehole measurements and paleoclimate simulations}

The consistency of the Lut2004 reconstruction with borehole temperature-depth profiles and with paleoclimate simulations is assessed in this section. The five logs of borehole measurements (M1, M2, M3, M4 and M5) are shown in Fig. 1a. Their corresponding inverse geothermal gradients were estimated using linear regressions applied to the data from the bottom 140-180 m (Fig. 1b). Owing to the deposition of fine material at the bottom of the borehole, there is a local change in thermal conductivity at about $180 \mathrm{~m}$. As the borehole was drilled in a very homogeneous granite batholith, these changes are not due to changes in the geological formation. In the present study, depths $>180 \mathrm{~m}$ are not used for gradient estimations. These gradients range from approximately 46 to $48 \mathrm{~m}^{\circ} \mathrm{C}^{-1}$ (ca. $0.021^{\circ} \mathrm{C} \mathrm{m}^{-1}$ ). The corresponding root-mean squared error (RMSE) of each estimated linear model is always $<0.01{ }^{\circ} \mathrm{C}$ (R-square adjusted $>99.9 \%$ ), which means that the errors in the estimation of the geothermal gradients have only minor impacts on the subsequent temperature-depth anomalies. The low borehole depths require a word of caution, as some authors have indicated that a depth of $200 \mathrm{~m}$ may be too shallow for climate change assessments (Beltrami et al., 2011; Hamza et al., 2007; Majorowicz et al., 1999). Indeed, the Global Database of Borehole Temperatures and Climate Reconstruc-
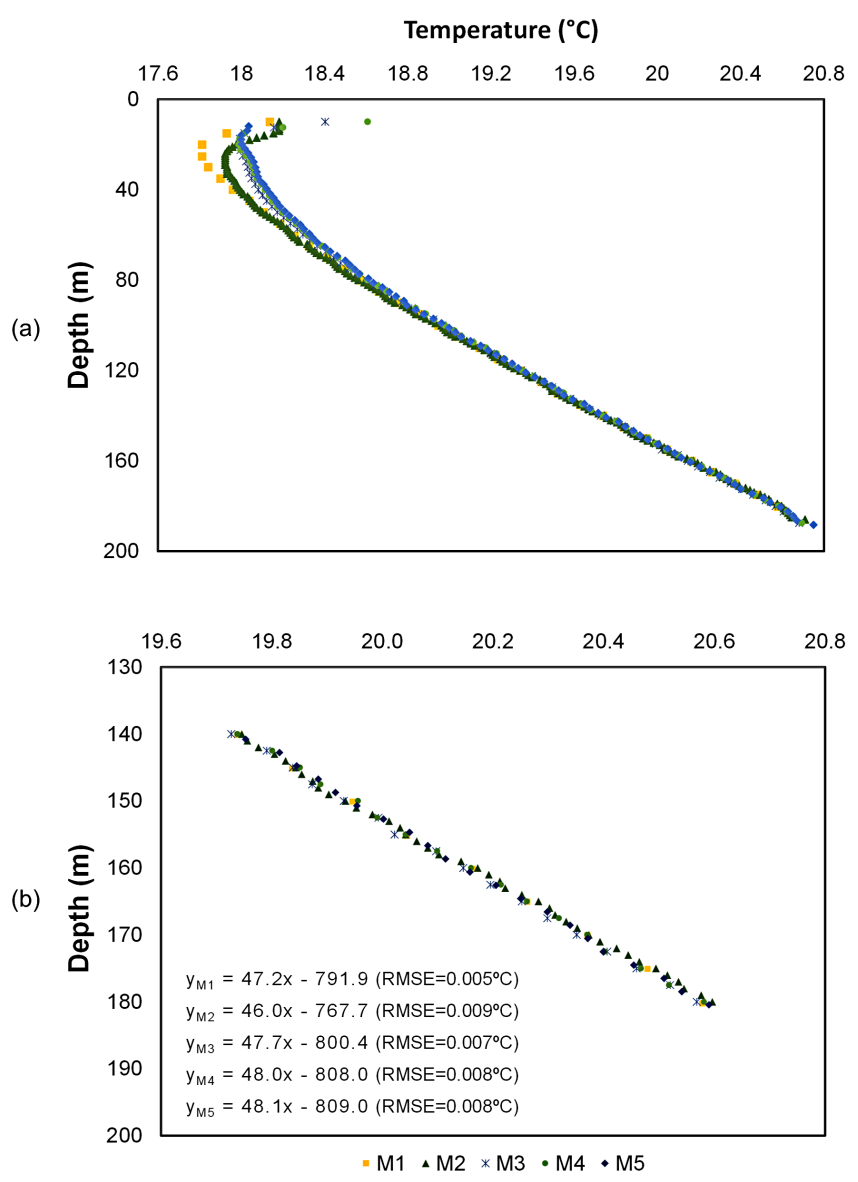

Figure 1. (a) Borehole temperature logs (temperature vs. depth) for M1, M2, M3, M4 and M5 from the Évora observatory (cf. legends). (b) The same as (a), but only for the data from the bottom 140$180 \mathrm{~m}$. The outlined equations of the respective regression lines (omitted) represent the corresponding estimated geothermal gradients (slope of the linear regression line).

tions from the University of Michigan and the World Data Center for Paleoclimatology consider a depth of $200 \mathrm{~m}$ as a minimum requirement for past climate reconstruction (Pollack and Huang, 2000). Beltrami et al. (2011) also demonstrated that the maximum depth of borehole profiles can have a large impact on temperature-depth anomalies. Since no other geothermal-paleoclimatological observatory is available in Portugal, the conclusions derived from these borehole profiles may be provisional.

The five temperature-depth anomaly profiles (M1-5) are reproduced in Fig. 2a with their estimated geothermal gradients having been removed. M1, M2, M3 and M4 show a more pronounced near-surface warming than M5. Overall, these profiles suggest strong recent-past warming trends in near-surface air temperatures.

The synthetic temperature-depth anomaly profiles, generated from the Lut2004 reconstruction and from the two paleoclimate simulations, are also shown in Fig. 2a. The 11-year 


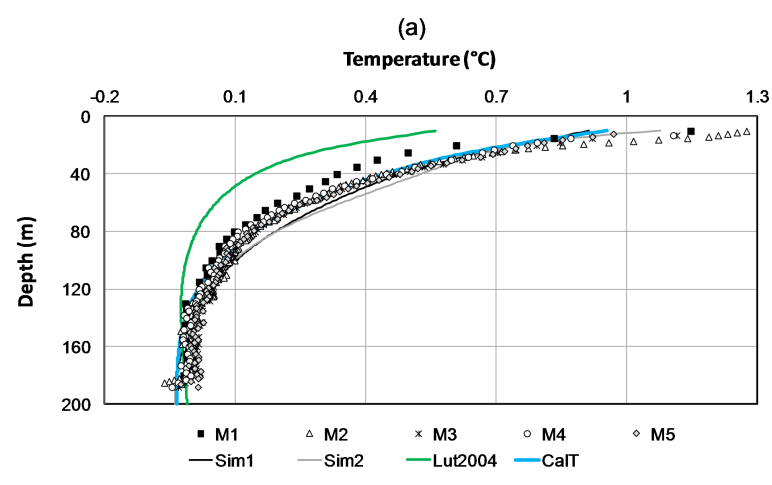

(b)

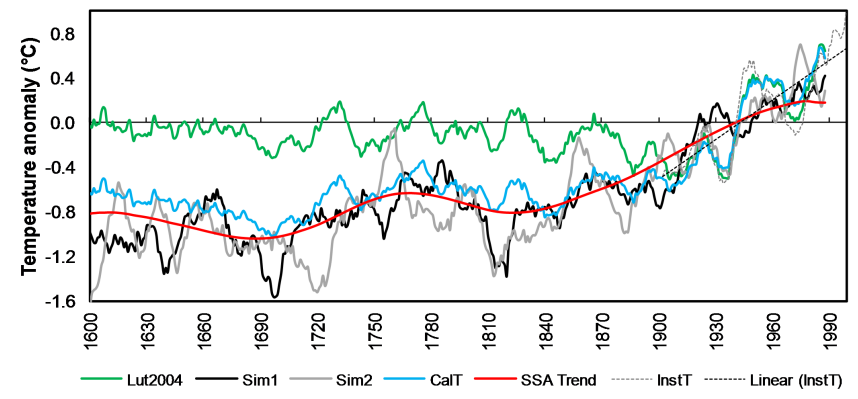

Figure 2. (a) Temperature-depth anomaly profiles for M1, M2, M3, M4 and M5, with respect to the estimated geothermal gradients in Fig. 1b, along with the synthetic profiles generated from Lut2004 (reconstructed temperature), CalT (calibrated temperature), and Sim1 and Sim2 (paleoclimate simulations) retrieved for a grid box near Lisbon, Portugal (cf. legends). (b) Chronograms of the 11-year running mean anomalies of Lut2004, CalT, and Sim1 and Sim 2 for the period of 1600-1989. The SSA-filtered ensemble mean temperature from the two simulations (SSA trend) is also displayed. The 11-year running means of InstT (instrumental annual mean temperature) anomalies are depicted for the period of 19011999 , along with the respective linear trend. Note that anomalies in each series are with respect to their common period (1901-1989).

running means of their anomalies over the period 1600-1989 are plotted in Fig. 2b. The chronograms of the two simulations, as well as their individual profiles, are indeed very similar to the corresponding ensemble mean chronograms and profiles (not shown). In fact, the correlation coefficient between the 11-year running means of the two simulations is as high as +0.82 . This is indicative of the large influence of external forcings in the long-term variability in temperature. Conversely to the simulations, which exhibit a strong warming trend since the 1830s, Lut2004 only depicts a recent-past upward trend and a cooling trend during the nineteenth century (Fig. 2b). Although the recent-past warming trend in Lut2004 is clearly corroborated by InstT, the cooling trend is neither supported by simulations (Fig. 2b) nor by any scientific evidence from previous studies. As a result, the synthetic temperature-depth anomaly profile obtained from Lut2004 is clearly different from the profiles obtained from the five borehole measurements and from the paleoclimate simulations (Fig.2a).

The discussion above suggests a remarkable agreement between the low-frequency variability in near-surface temperature from two independent sources (borehole measurements and paleoclimate simulations driven by reconstructed forcing). However, whereas the paleoclimate simulations agree well with the borehole temperature-depth profiles, the reconstructed temperature for Portugal (Lut2004) is not entirely consistent with the long-term trends revealed by these new sources. In fact, its linear trend is nearly 0 over the whole period and there is no signature of cool or warm periods. This disagreement between simulations and Lut2004 was already reported by Gómez-Navarro et al. (2011). As such, the low-frequency variability in the Lut2004 reconstruction are herein adjusted to be more coherent with the borehole data and simulations. To achieve this aim, the ensemble mean temperature from the two simulations was lowpass filtered by a two-order SSA. The filtered series (SSA trend in Fig. 2b) highlights the signature of the external forcings in near-surface temperature and was then added to the Lut2004 reconstruction. The resulting calibrated series $($ CalT $=$ Lut2004 + SSA trend $)$ is also shown in Fig. 2 b.

The SSA trend clearly shows a warming trend since the 1830s and a relatively cool period during the LMM (1670 1730). This is also in line with previous studies on the impact of solar activity on global temperatures (e.g. Eddy, 1983; Frenzel, 1994). The period from 1730 to 1800 recorded annual mean temperatures close to the baseline, followed by an anomalously cold period until the 1830 s, which is associated with the Dalton Minimum, also a period of low solar activity (Wagner and Zorita, 2005). The strong upward trend in CalT from the 1830s onwards is now in clear agreement with the paleoclimate simulations and Inst T (in the twentieth century). The LMM (ca. 1670-1730) and Dalton Minimum (ca. 1790-1830) are also clearly depicted in CalT. Furthermore, the temperature-depth anomaly profile from CalT is similar to the profiles from the five borehole measurements and paleoclimate simulations (Fig. 2a). This represents an important validation of CalT.

\subsection{Consistency with instrumental data}

The consistency between InstT and CalT has been assessed by a linear regression in their common period (1901-1989). The corresponding scatter plot shows that linear regression provides a good fitting, with a correlation coefficient above 0.90 (Fig. 3), explaining about $82 \%$ of the total variance (R-square adjusted), and an RMSE of 0.22 . According to Fisher's test, this least-squares linear regression model is statistically significant at a $99 \%$ confidence level $(p<0.01)$. A bootstrap procedure with 10000 resamples shows that the $95 \%$ confidence interval for the correlation coefficient between Inst T and CalT is [0.87, 0.93], supporting Fisher's test. Therefore, CalT clearly reproduces the observed temperature 


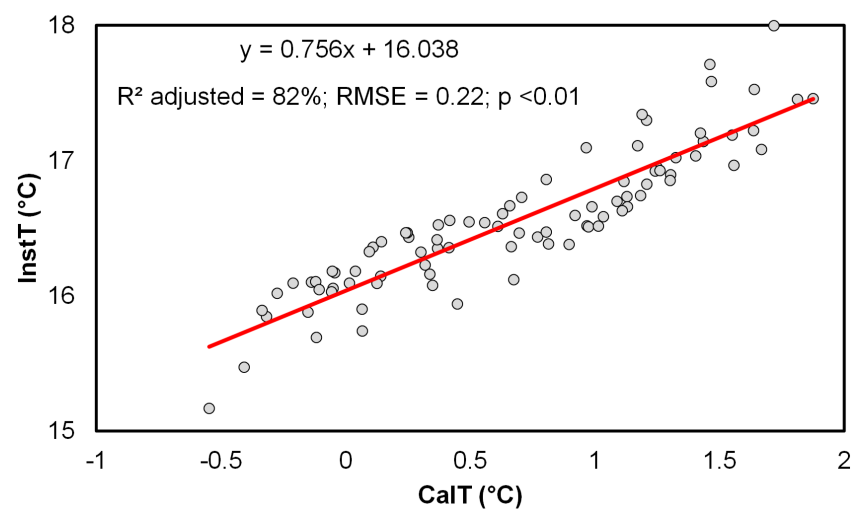

Figure 3. Scatter plot of InstT and CalT anomalies over their common period (1901-1989). The corresponding regression line, calibration equation and R-squared measure (determination coefficient) are also shown.

in Portugal in InstT. A three-order polynomial fitting, with a robust regression using the bisquare weighting method, provides a slightly better adjustment (R-square adjusted of $83 \%$ and RMSE of 0.21), but its extrapolation for the lowest temperatures (outside the range of values used in the model fitting, not shown) is not reliable and was discarded. The corresponding linear regression polynomial is applied to a secondstage adjustment of location and scale parameters in CalT. This allows expressing CalT in absolute temperature values instead of anomalies (Fig. 4a). Additionally, taking into account the high coherency between CalT and InstT, CalT was extended from 1989 to 1999 using InstT values. In order to confirm long-term trends in CalT, the non-parametric progressive Mann-Kendall test is applied (Sneyers, 1990, 1992). The forward and backward Kendall $t$ parameters for CalT jointly depict a warming trend from the 1830s onwards; this is particularly noteworthy from the 1930s onwards (Fig. 4b).

The uncertainties in the CalT series are a combination of the original uncertainties in the Lut2004 data set plus additional uncertainties related to the non-linear trend used in the adjustment. The uncertainties in the Lut2004 data set are discussed in Luterbacher et al. (2004) but are only available for the European mean reconstruction. Hence, it is not possible to have a local estimate of these uncertainties. The uncertainties in trend estimation can be estimated through the assessment of the consistency between Sim1 and Sim2. For this purpose, the SSA filtering was applied separately to Sim1 and Sim2. The mean absolute difference between the two non-linear trends obtained from Sim1 and Sim2 provides a measure of the uncertainty related to the simulations. It has an approximate value of $0.05^{\circ} \mathrm{C}$. However, this number provides just a lower bound, since it does not explicitly consider uncertainties related to the simulation itself, which are difficult to assess due to the limited number of available simulations with similar characteristics.

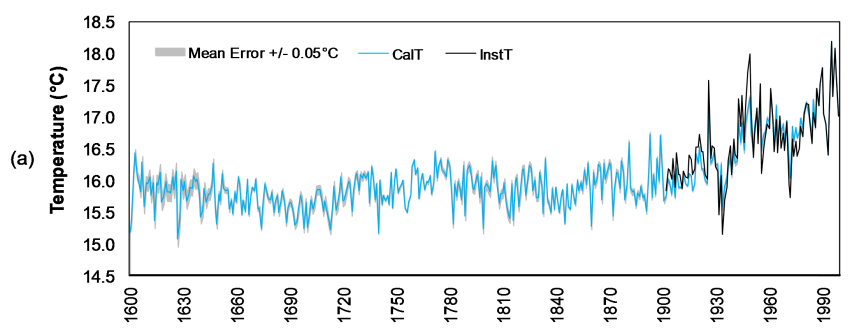

(b)

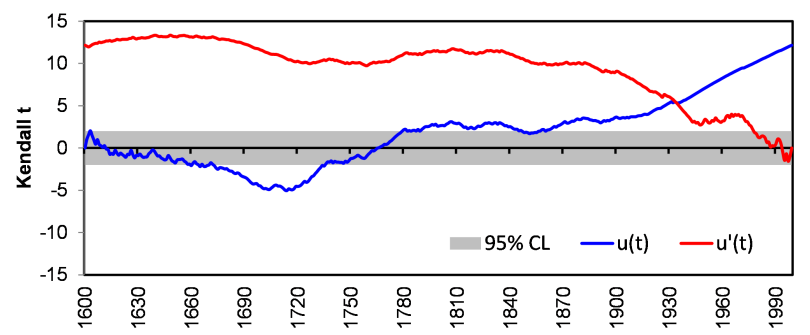

Figure 4. Chronogram of (a) CalT (calibrated annual mean temperature) in the period of 1600-1999 and InstT (instrumental series) in the period of 1901-1999. Estimated errors are shaded grey, with a mean error of $0.05^{\circ} \mathrm{C}$. (b) Forward $(u(t))$ and backward $\left(u^{\prime}(t)\right)$ series of the normalized Kendall $t$ parameter from the progressive Mann-Kendall analysis of CalT. The $95 \%$ confidence interval for the no-trend hypothesis in grey shading.

\subsection{Consistency with precipitation indices}

In previous studies, temperature in southern Portugal was analysed during the LMM (1675-1715) by Alcoforado et al. (2000), and during the eighteenth century by Taborda et al. (2004) and Alcoforado et al. (2012). In these studies, research was based on documentary evidence, such as diaries, ecclesiastical rogation ceremonies (pro pluvia and pro serenitate), Misericórdias and municipal institutional sources, as well as on early instrumental data. From this documentary evidence, basic data were transformed into indices on an ordinal scale, following the methodology developed by Pfister (1995). Monthly temperatures were originally indexed on a scale from 0 to \pm 1 . Annual indices (December-November) can then vary from 0 to \pm 12 . The consistency between CalT and the corresponding annual indexed temperatures is assessed by their respective scatter plots (Fig. 5). For a perfect agreement, the documented temperature extremes (cold or hot years) should be reflected by coherent CalT anomalies, i.e. all data pairs in the scatter plots should be either in the top-right or bottom-left quadrants (positively aligned series). There is an overall agreement between CalT and the annual temperature index ( $>80 \%$ of all years are in the topright or bottom-left quadrants, with a correlation coefficient of 0.76 ). Therefore, this agreement also provides a validation of CalT for the period of 1675-1715. However, as the SSA filtering does not significantly modify the interannual variability within this relatively short time period (LMM), 


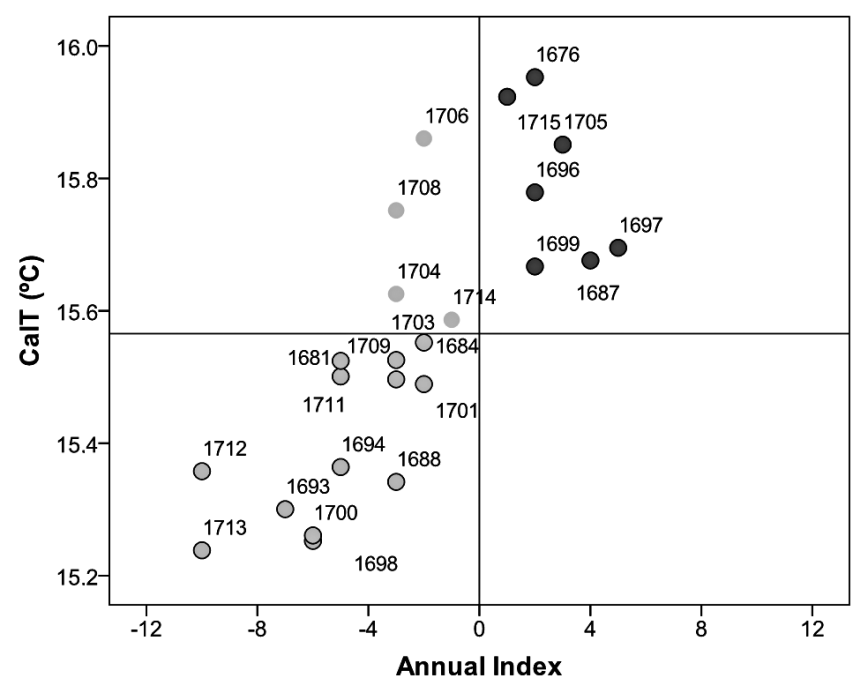

Figure 5. Scatter plot of CalT in the period of $1675-1715$ as a function of the annual temperature indices. Light (dark) grey circles represent cold (hot) years from documentary evidence. Circles with black edges indicate agreement between the two data sets. Years with " 0 " index are omitted for the sake of readability of the plot. The horizontal line corresponds to CalT mean. Some labels are omitted for the sake of clarity.

the aforementioned agreement also applies between Lut2004 and the annual temperature index (not shown).

\section{Summary and conclusions}

The consistency of the reconstructed annual temperature series in Portugal (Lut2004) is assessed by using five borehole temperature-depth profiles, synthetic temperaturedepth profiles generated from both the Lut2004 reconstruction and paleoclimate simulations, instrumental data (InstT) and indexed temperatures during the LMM. While the paleoclimate simulations agree well with the borehole temperature-depth profiles with regard to the long-term variability, the same does not apply to the Lut2004 reconstruction. In fact, the long-term trends in Lut2004 are not fully consistent with borehole data and simulations. The late Maunder and Dalton minima, clearly reflected in the paleoclimate simulations and well-documented in the literature, in association with changes in solar activity (Eddy, 1983), are absent from the Lut2004 reconstruction. Moreover, there is a cooling trend throughout the nineteenth century that is not supported by previous studies. Therefore, the Lut2004 reconstruction was calibrated by adjusting its low-frequency variability to the paleoclimatic simulations, also in agreement with local borehole data. Documentary sources in Portugal during the LMM (1675-1715) also show high agreement with CalT, thus providing an additional validation for the LMM.
These results suggest some inconsistencies in the lowfrequency variability in temperature in Portugal between the Lut2004 reconstruction and borehole data or simulations. In effect, the absence of clear long-term trends in Lut2004 is not coherent with the significant changes in radiative forcing throughout the last 400 years and the important role played by these external forcings on temperature variability over western Iberia (Gómez-Navarro et al., 2012). The frequent temporal gaps in the pre-instrumental records and the substantial lack of natural proxies with clear climatic signals in Portugal (Alcoforado et al., 2012; Camuffo et al., 2010; Luterbacher et al., 2006) may partially explain this limitation in the reproduction of the low-frequency variability in the Lut2004 reconstruction. An important loss of low-frequency variance caused by the method used in Lut2004 was also found by von Storch et al. (2009). Nevertheless, a more detailed assessment of the causes for this shortcoming is beyond the scope of the present study, as this study does not develop a new reconstruction for comparison but rather an adjustment of an existing reconstruction.

CalT adjusts the low-frequency variability in the Lut2004 reconstruction so as to be more consistent with local borehole measurements and regional climate simulations. It can thus be of foremost relevance in forthcoming research on climatic variability in Portugal. A reliable representation of the low-frequency variability in temperature in Portugal, including its long-term trends, is critical for understanding the role played by external vs. internal forcings in regional climate variability and change. Due to the relatively coarse spatial resolution of data generated by state-of-the-art GCMs, the latter are not suitable for regional-scale assessments. Since such scales are precisely the focus of this study, temperature series from two high-resolution regional paleoclimatic simulations ( $\mathrm{Sim} 1$ and Sim2) are employed instead of GCM runs. These two simulations were documented and validated in previous studies. Unfortunately, there are only two available simulations covering Portugal with such high-resolution characteristics. Hence, it is not possible to increase the ensemble size of model simulations, though it would be very useful for uncertainty assessments. In forthcoming research, new regional paleoclimatic simulations over Portugal, also using different models, should be used to enhance the robustness and evaluate the significance of the current adjustment.

Acknowledgements. This study was carried out within the framework of the project "Reconstruction and model simulations of past climate in Portugal, using documentary and early instrumental sources - Klimhist" and was supported by national funds from FCT (Portuguese Foundation for Science and Technology) under grant numbers PTDC/AAC-CLI/119078/2010 and UID/AGR/04033/2013.

Edited by: S. Bronnimann 


\section{References}

Ahmed, M., Anchukaitis, K. J., Asrat, A., Borgaonkar, H. P., Braida, M., Buckley, B. M., Buntgen, U., Chase, B. M., Christie, D. A., Cook, E. R., Curran, M. A. J., Diaz, H. F., Esper, J., Fan, Z. X., Gaire, N. P., Ge, Q. S., Gergis, J., Gonzalez-Rouco, J. F., Goosse, H., Grab, S. W., Graham, N., Graham, R., Grosjean, M., Hanhijarvi, S. T., Kaufman, D. S., Kiefer, T., Kimura, K., Korhola, A. A., Krusic, P. J., Lara, A., Lezine, A. M., Ljungqvist, F. C., Lorrey, A. M., Luterbacher, J., Masson-Delmotte, V., McCarroll, D., McConnell, J. R., McKay, N. P., Morales, M. S., Moy, A. D., Mulvaney, R., Mundo, I. A., Nakatsuka, T., Nash, D. J., Neukom, R., Nicholson, S. E., Oerter, H., Palmer, J. G., Phipps, S. J., Prieto, M. R., Rivera, A., Sano, M., Severi, M., Shanahan, T. M., Shao, X. M., Shi, F., Sigl, M., Smerdon, J. E., Solomina, O. N., Steig, E. J., Stenni, B., Thamban, M., Trouet, V., Turney, C. S. M., Umer, M., van Ommen, T., Verschuren, D., Viau, A. E., Villalba, R., Vinther, B. M., von Gunten, L., Wagner, S., Wahl, E. R., Wanner, H., Werner, J. P., White, J. W. C., Yasue, K., Zorita, E., and Consortium, P. K.: Continental-scale temperature variability during the past two millennia, Nat. Geosci., 6, 339-346, 2013.

Alcoforado, M. J., Nunes, M. F., Garcia, J. C., and Taborda, J. P.: Temperature and precipitation reconstruction in southern Portugal during the late Maunder Minimum (AD 1675-1715), Holocene, 10, 333-340, 2000.

Alcoforado, M. J., Vaquero, J. M., Trigo, R. M., and Taborda, J. P.: Early Portuguese meteorological measurements (18th century), Clim. Past, 8, 353-371, doi:10.5194/cp-8-353-2012, 2012.

Beltrami, H. and Mareschal, J.-C.: Resolution of ground temperature histories inverted from borehole temperature data, Global Planet. Change, 11, 57-70, 1995.

Beltrami, H. and Bourlon, E.: Ground warming patterns in the Northern Hemisphere during the last five centuries, Earth Planet. Sc. Lett., 227, 169-177, 2004.

Beltrami, H., González-Rouco, J. F., and Stevens, M. B.: Subsurface temperatures during the last millennium: model and observation, Geophys. Res. Lett., 33, L09705, doi:10.1029/2006GL026050, 2006.

Beltrami, H., Smerdon, J. E., Matharoo, G. S., and Nickerson, N.: Impact of maximum borehole depths on inverted temperature histories in borehole paleoclimatology, Clim. Past, 7, 745-756, doi:10.5194/cp-7-745-2011, 2011.

Bodri, L. and Čermák, V.: Reconstruction of remote climate changes from borehole temperatures, Global Planet. Change, 15, 47-57, 1997.

Brázdil, R., Pfister, C., Wanner, H., Storch, H., and Luterbacher, J.: Historical Climatology In Europe - The State Of The Art, Clim. Change, 70, 363-430, 2005.

Brázdil, R., Dobrovolný, P., Luterbacher, J., Moberg, A., Pfister, C., Wheeler, D., and Zorita, E.: European climate of the past 500 years: new challenges for historical climatology, Clim. Change, 101, 7-40, 2010.

Camuffo, D., Bertolin, C., Barriendos, M., Dominguez-Castro, F., Cocheo, C., Enzi, S., Sghedoni, M., Valle, A., Garnier, E., Alcoforado, M. J., Xoplaki, E., Luterbacher, J., Diodato, N., Maugeri, M., Nunes, M. F., and Rodriguez, R.: 500-year temperature reconstruction in the Mediterranean Basin by means of documentary data and instrumental observations, Clim. Change, 101, 169-199, 2010
Camuffo, D., Bertolin, C., Diodato, N., Cocheo, C., Barriendos, M., Dominguez-Castro, F., Garnier, E., Alcoforado, M. J., and Nunes, M. F.: Western Mediterranean precipitation over the last 300 years from instrumental observations, Clim. Change, 117, 85-101, 2013.

Carslaw, H. S. and Jaeger, J. C.: Conduction of Heat in Solids, Oxford Univ. Press, New York, 1959.

Cermak, V. and Rybach, L.: Thermal conductivity and specific heat of minerals and rocks, in: Landolt-Börnstein - Group V Geophysics, edited by: Subvolume, A. and Angenheister, G., Springer Berlin Heidelberg, 341-343, 1982.

Chouinard, C. and Mareschal, J. C.: Selection of borehole temperature depth profiles for regional climate reconstructions, Clim. Past, 3, 297-313, doi:10.5194/cp-3-297-2007, 2007.

Correia, A. and Šafanda, J.: Preliminary ground surface temperature history in mainland Portugal reconstructed from borehole temperature logs, Tectonophysics, 306, 269-275, doi:10.1016/S0040-1951(99)00060-8, 1999.

Correia, A. and Šafanda, J.: Ground surface temperature history at a single site in southern Portugal reconstructed from borehole temperatures, Global Planet. Change, 29, 155-165, 2001.

Eddy, J. A.: The Maunder Minimum - a Reappraisal, Sol. Phys., 89, 195-207, 1983.

Elsner, J. B. and Tsonis, A. A.: Singular spectrum analysis: a new tool in time series analysis, Plenum Press, New York, London, 1996.

Frenzel, B.: Climatic Trends and anomalies in Europe 1675-1715, High resolution spatio-temporal reconstructions from direct meteorological observations and proxy data. Methods and Results, Gustav Fischer Verlag, Stuttgart, Jena and New York, 1994.

Ghil, M. and Vautard, R.: Interdecadal Oscillations and the Warming Trend in Global Temperature Time-Series, Nature, 350, 324 327, doi:10.1038/350324a0, 1991.

Gómez-Navarro, J. J., Montavez, J. P., Jerez, S., Jimenez-Guerrero, P., Lorente-Plazas, R., Gonzalez-Rouco, J. F., and Zorita, E.: A regional climate simulation over the Iberian Peninsula for the last millennium, Clim. Past, 7, 451-472, doi:10.5194/cp-7-451-2011, 2011.

Gómez-Navarro, J. J., Montávez, J. P., Jiménez-Guerrero, P., Jerez, S., Lorente-Plazas, R., González-Rouco, J. F., and Zorita, E.: Internal and external variability in regional simulations of the Iberian Peninsula climate over the last millennium, Clim. Past, 8, 25-36, doi:10.5194/cp-8-25-2012, 2012.

González-Rouco, F., von Storch, H., and Zorita, E.: Deep soil temperature as proxy for surface air-temperature in a coupled model simulation of the last thousand years, Geophys. Res. Lett., 30, 2116, doi:10.1029/2003GL018264, 2003.

González-Rouco, J. F., Beltrami, H., Zorita, E., and von Storch, H.: Simulation and inversion of borehole temperature profiles in surrogate climates: Spatial distribution and surface coupling, Geophys. Res. Lett., 33, L01703, doi:10.1029/2005GL024693, 2006.

González-Rouco, J. F., Beltrami, H., Zorita, E., and Stevens, M. B.: Borehole climatology: a discussion based on contributions from climate modeling, Clim. Past, 5, 97-127, doi:10.5194/cp-5-972009, 2009.

Gouirand, I., Moberg, A., and Zorita, E.: Climate variability in Scandinavia for the past millennium simulated by an atmosphere-ocean general circulation model, Tellus A, 59, 3049, doi:10.1111/j.1600-0870.2006.00207.x, 2007. 
Hamza, V. M., Cavalcanti, A. S. B., and Benyosef, L. C. C.: Surface thermal perturbations of the recent past at low latitudes - inferences based on borehole temperature data from Eastern Brazil, Clim. Past, 3, 513-526, 2007,

http://www.clim-past.net/3/513/2007/.

Harris, R. N. and Chapman, D. S.: Geothermics and climate change: 1. Analysis of borehole temperatures with emphasis on resolving power, J. Geophys. Res.-Sol. Ea., 103, 7363-7370, 1998.

Harris, R. N. and Gosnold, W. D.: Comparisons of borehole temperature-depth profiles and surface air temperatures in the northern plains of the USA, Geophys. J. Int., 138, 541-548, 1999.

Hartmann, A. and Rath, V.: Uncertainties and shortcomings of ground surface temperature histories derived from inversion of temperature logs, J. Geophys. Eng., 2, 299-311, doi:10.1088/1742-2132/2/4/S02, 2005.

IPCC: Climate Change 2013: The Physical Science Basis, Contribution of Working Group I to the Fifth Assessment Report of the Intergovernmental Panel on Climate Change, edited by: Stocker, T. F., Qin, D., Plattner, G.-K., Tignor, M., Allen, S. K., Boschung, J., Nauels, A., Xia, Y., Bex, V., and Midgley, P. M., Cambridge University Press, Cambridge, United Kingdom and New York, NY, USA, 1535 pp., 2013.

Jones, P. D., Briffa, K. R., Osborn, T. J., Lough, J. M., van Ommen, T. D., Vinther, B. M., Luterbacher, J., Wahl, E. R., Zwiers, F. W., Mann, M. E., Schmidt, G. A., Ammann, C. M., Buckley, B. M., Cobb, K. M., Esper, J., Goosse, H., Graham, N., Jansen, E., Kiefer, T., Kull, C., Kuttel, M., Mosley-Thompson, E., Overpeck, J. T., Riedwyl, N., Schulz, M., Tudhope, A. W., Villalba, R., Wanner, H., Wolff, E., and Xoplaki, E.: High-resolution palaeoclimatology of the last millennium: a review of current status and future prospects, Holocene, 19, 3-49, 2009.

Klein Tank, A. M. G., Wijngaard, J. B., Können, G. P., Böhm, R., Demarée, G., Gocheva, A., Mileta, M., Pashiardis, S., Hejkrlik, L., Kern-Hansen, C., Heino, R., Bessemoulin, P., MüllerWestermeier, G., Tzanakou, M., Szalai, S., Pálsdóttir, T., Fitzgerald, D., Rubin, S., Capaldo, M., Maugeri, M., Leitass, A., Bukantis, A., Aberfeld, R., van Engelen, A. F. V., Forland, E., Mietus, M., Coelho, F., Mares, C., Razuvaev, V., Nieplova, E., Cegnar, T., Antonio López, J., Dahlström, B., Moberg, A., Kirchhofer, W., Ceylan, A., Pachaliuk, O., Alexander, L. V., and Petrovic, P.: Daily dataset of 20th-century surface air temperature and precipitation series for the European Climate Assessment, Int. J. Climatol., 22, 1441-1453, 2002.

Legutke, S. and Voss, R.: The Hamburg atmosphere-ocean coupled circulation model ECHOG, Germany DKRZ Tech. Rep. 18, Dtsch. Klimarechenzentrum, Hamburg, 1999.

Li, B., Nychka, D. W., and Ammann, C. M.: The Value of Multiproxy Reconstruction of Past Climate, J. Am. Stat. Assoc., 105, 883-895, 2010.

Luterbacher, J., Dietrich, D., Xoplaki, E., Grosjean, M., and Wanner, H.: European seasonal and annual temperature variability, trends, and extremes since 1500, Science, 303, 1499-1503, 2004.

Luterbacher, J., Xoplaki, E., Casty, C., Wanner, H., Pauling, A., Küttel, M., Rutishauser, T., Brönnimann, S., Fischer, E., Fleitmann, D., Gonzalez-Rouco, F. J., García-Herrera, R., Barriendos, M., Rodrigo, F., Gonzalez-Hidalgo, J. C., Saz, M. A., Gimeno, L., Ribera, P., Brunet, M., Paeth, H., Rimbu, N., Felis, T., Jacobeit, J., Dünkeloh, A., Zorita, E., Guiot, J., Türkes, M., Al- coforado, M. J., Trigo, R., Wheeler, D., Tett, S., Mann, M. E., Touchan, R., Shindell, D. T., Silenzi, S., Montagna, P., Camuffo, D., Mariotti, A., Nanni, T., Brunetti, M., Maugeri, M., Zerefos, C., Zolt, S. D., Lionello, P., Nunes, M. F., Rath, V., Beltrami, H., Garnier, E., and Ladurie, E. L. R.: Chapter 1 Mediterranean climate variability over the last centuries: A review, in: Mediterranean climate variability, edited by: Lionello, P., MalanotteRizzoli, P., and Boscolo, R., Elsevier, 27-148, 2006.

Majorowicz, J. A., Šafanda, J., Harris, R. N., and Skinner, W. R.: Large ground surface temperature changes of the last three centuries inferred from borehole temperatures in the Southern Canadian Prairies, Saskatchewan, Global Planet. Change, 20, 227 241, 1999.

Mareschal, J. C. and Beltrami, H.: Evidence for recent warming from perturbed geothermal gradients: examples from eastern Canada, Clim. Dynam., 6, 135-143, 1992.

New, M., Hulme, M., and Jones, P.: Representing twentieth-century space-time climate variability. Part II: Development of 19011996 monthly grids of terrestrial surface climate, J. Climate, 13, 2217-2238, 2000.

Nielsen, S. B. and Beck, A. E.: Heat-Flow Density Values and Paleoclimate Determined from Stochastic Inversion of 4 Temperature Depth Profiles from the Superior Province of the Canadian Shield, Tectonophysics, 164, 345-359, 1989.

Pfister, C.: Monthly temperature and precipitation in central Europe from 1525-1979: quantifying documentary evidence on weather and its effects, in: Climate since A.D. 1500, edited by: Bradley, R. S. and Jones, P. D., Routledge, London, 118-142, 1995.

Plaut, G. and Vautard, R.: Spells of Low-Frequency Oscillations and Weather Regimes in the Northern-Hemisphere, J. Atmos. Sci., 51, 210-236, 1994.

Pollack, H. N. and Huang, S. P.: Climate reconstruction from subsurface temperatures, Annu. Rev. Earth. Pl. Sc., 28, 339-365, 2000.

Pollack, H. N., Huang, S. P., and Smerdon, J. E.: Five centuries of climate change in Australia: the view from underground, J. Quaternary Sci., 21, 701-706, 2006.

Roeckner, E., Arpe, K., Bengtsson, L., Christoph, M., Claussen, M., Dumenil, L., Esch, M., Giorgetta, M., Schlese, U., and Schulzweida, U.: The atmospheric general circulation model ECHAM4: model description and simulation of present-day climate, Max-Planck-Institut für Meterologie, Hamburg, Germany Tech. Rep., 218, 90 pp., 1996.

Šafanda, J., Rajver, D., Correia, A., and Dedecek, P.: Repeated temperature logs from Czech, Slovenian and Portuguese borehole climate observatories, Clim. Past, 3, 453-462, doi:10.5194/cp-3453-2007, 2007.

Shen, P. Y. and Beck, A. E.: Paleoclimate Change and Heat-Flow Density Inferred from Temperature Data in the Superior Province of the Canadian Shield, Global Planet. Change, 98, 143-165, 1992.

Sneyers, R.: On the Statistical Analysis of Series of Observations, Secretariat of the World Meteorological Organization, Geneve, Switzerland, 1990.

Sneyers, R.: Use and measure of statistical methods for detection of climatic change, in: Climate Change Detection Project, Report on the Informal Planning Meeting on Statistical Procedures for Climate Change Detection, WCDMP, 20, Geneve, Switzerland, 176-181, 1992. 
Stevens, M. B., González-Rouco, J. F., and Beltrami, H.: North American climate of the last millennium: Underground temperatures and model comparison, J. Geophys. Res.-Earth, 113, F01008, doi:10.1029/2006JF000705, 2008.

Taborda, J. P., Alcoforado, M. J., and Garcia, J. C.: Climate in southern Portugal in the 18th century. Reconstruction based on documentary and early instrumental sources (in Portuguese, with extended English summary), University of Lisbon, Geo-Ecologia, 2, CEG, Lisboa, ISBN: 972-636-144-3, 2004.

Vautard, R., Yiou, P., and Ghil, M.: Singular-Spectrum Analysis - a Toolkit for Short, Noisy Chaotic Signals, Physica D, 58, 95-126, 1992.

von Storch, H., Zorita, E., and Gonzalez-Rouco, F.: Assessment of three temperature reconstruction methods in the virtual reality of a climate simulation, Int. J. Earth Sci., 98, 67-82, 2009.
Wagner, S. and Zorita, E.: The influence of volcanic, solar and the Dalton Minimum (1790-1830): CO2 forcing on the temperatures in a model study, Clim. Dyn., 25, 205-218, 2005.

Xoplaki, E., Luterbacher, J., Paeth, H., Dietrich, D., Steiner, N., Grosjean, M., and Wanner, H.: European spring and autumn temperature variability and change of extremes over the last half millennium, Geophys. Res. Lett., 32, L15713, doi:10.1029/2005GL023424, 2005.

Zorita, E., González-Rouco, J. F., von Storch, H., Montávez, J. P., and Valero, F.: Natural and anthropogenic modes of surface temperature variations in the last thousand years, Geophys. Res. Lett., 32, L08707, doi:10.1029/2004GL021563, 2005.

Zorita, E., Gonzalez-Rouco, F., and von Storch, H.: Comments on "Testing the Fidelity of Methods Used in Proxy-Based Reconstructions of Past Climate", J. Climate, 20, 3693-3698, 2007. 